\title{
Analysis of the applicability of polymeric solutions as cooling fluid in the quenching of low-alloy steels
}

\author{
Eduardo da Rosa Vieira ${ }^{1}$ \\ Jorge Luis Braz Medeiros $2 *$ (D) \\ Luciano Volcanoglo Biehl ${ }^{2}$ \\ Vagner Machado Costa ${ }^{3}$ \\ Carlos Otávio Damas Martins ${ }^{4}$ \\ José de Souza ${ }^{5}$
}

\begin{abstract}
Engineering manufacturing involves the application of different steps to guarantee materials processability and performance in service. This, normally, requires machining, conformation, surface, and heat treatments. A modern concern is related to the process sustainability, the manufacturing capacity to achieve the required properties at low environmental impacts. In this sense, this work evaluated the application of the Polyalkylene Glycol solution (PAG) as a cooling medium of AISI 4140 low alloy steels. The materials were quenched in PAG, water, and Mineral Oil. The medium was compared by the martensite content and hardness distribution results. The results showed a significant advance in the PAG application, which guarantees a higher homogenization on martensite distribution at a low decrease in the hardness profile.
\end{abstract}

Keywords: Manufacturing; Quenching; Polymer solutions; Low alloy steels.

\section{Introduction}

Modern Engineering applies different types of processes to guarantee the components form and properties at low cost and environmental degradation [1-3]. During this process, the microstructure is modified to improve processability. At the final step, the microstructure is modified for performance, safety, and Structural Integrity [4]. In this stage, for most of steel manufacturing structural components, martensite is the target microstructure [5-7].

The martensite is a supersaturated carbon-iron reliable solution that combines high values of hardness and mechanical strength. The crystal high distortion (martensite is a Body Centered Tetragonal structure) and the restriction to the discordance's movements are the main reasons for the mechanical performance of this microstructure [8-12].

Quenching is the heat treatment that provides a martensite microstructural, where its proportion depends on steel composition and medium heat exchange capacity. Carbon is the principal element that promotes the formation of martensite in steels (normally applied between $0.3 \%$ to
$0.6 \%$, for toughness maintenance). Other elements, like Chromium (Cr), Molybdenum (Mo), Nickel (Ni) has major influenced in the austenite morphologic aspect and the heat exchange rate [8-13].

The success of the Quenching Heat Treatment is measured by the Hardness profile [6]. Hardenability is the material capacity of product martensite due the heat treatment. The Jominy plots usually determine it. It is affected by materials composition, grain size, and cooling medium [8-10].

The quenching process is divided into three stages:

1) Austenitization above $\mathrm{A} 3$ (Austenite has a Face Centered Cubic (FCC) crystalline structure that allocates a higher carbon content $(2.11 \%)$;

2) Rapid Cooling (this process must be fast enough to prevent carbon diffusion, promoting the distortion and formation of a high carbon saturated microstructure (martensite)).

\footnotetext{
I Pós-graduação em Engenharia Mecânica, Universidade Federal do Rio Grande do Sul - UFRGS, Porto Alegre, Brasil.

${ }^{2}$ Programa de Pós-graduação em Engenharia Mecânica, Universidade Federal do Rio Grande - FURG, RS, Brasil,

${ }^{3}$ Instituto Federal do Rio Grande do Sul - IFS, Rio Grande, RS, Brasil.

${ }^{4}$ Universidade Federal de Sergipe - UFS, Sergipe, Brasil.

${ }^{5}$ Fundação Escola Técnica Liberato Salzano Vieira da Cunha - FETLSVC, Novo Hamburgo, Brasil.

*Corresponding author: jorge.braz@furg.br
} 
3) Tempering (reduce residual stresses and brittleness) [8-12].

Figure 1 shows a typical representation of a Quenching cycle and a Time - Temperature - Transformation Diagram. Note that the presence of alloy elements can dislocate the $\mathrm{M}_{\mathrm{s}}$ (Martensite transformation Starting) and $\mathrm{M}_{\mathrm{f}}$ (Martensite transformation Finishing) curves in the right direction, increasing the materials Hardenability and lowering the Cooling rate [8].

Rapid Cooling on the quenching process can occur in three well-defined stages: steam capsule, boiling, and convection [8-13].

In the first stage, the heated material meets the fluid at room temperature. The liquid vaporizes instantly and forms a vapor blanket around the piece. This layer isolates the body from the cooling medium, allowing heat exchange only by radiation (at low cooling rates). When the heat is no longer sufficient to vaporize the fluid, boiling starts. In this second stage, the breaking of the steam capsule occurs, forming air bubbles that move up to the fluid surface and promoting the highest rates of heat exchange in the process. For most fluids, this rupture begins at the bottom of the part and gradually evolves until extinguished the entire layer. Finally, the material enters the convection stage, which again presents low heat exchange until the body achieve the thermal equilibrium with the fluid [8-13].

Figure 2 shows a representation of the cooling stages (a-c), Cooling and Cooling rate curves (d), and Jominy plots for different steels alloys (e) [9]. Note the influence of the alloy elements on Hardness maintenance through the distance from the quenched end.

Some harmful effects of the quenching process are related to distortion and residual stresses. The austenite to martensite phase transformation results in a volumetric expansion $(\mathrm{c} / \mathrm{a}=1+0,0467 \mathrm{x} \% \mathrm{C}$, depending on the carbon content). This variation originates the residual stresses, since

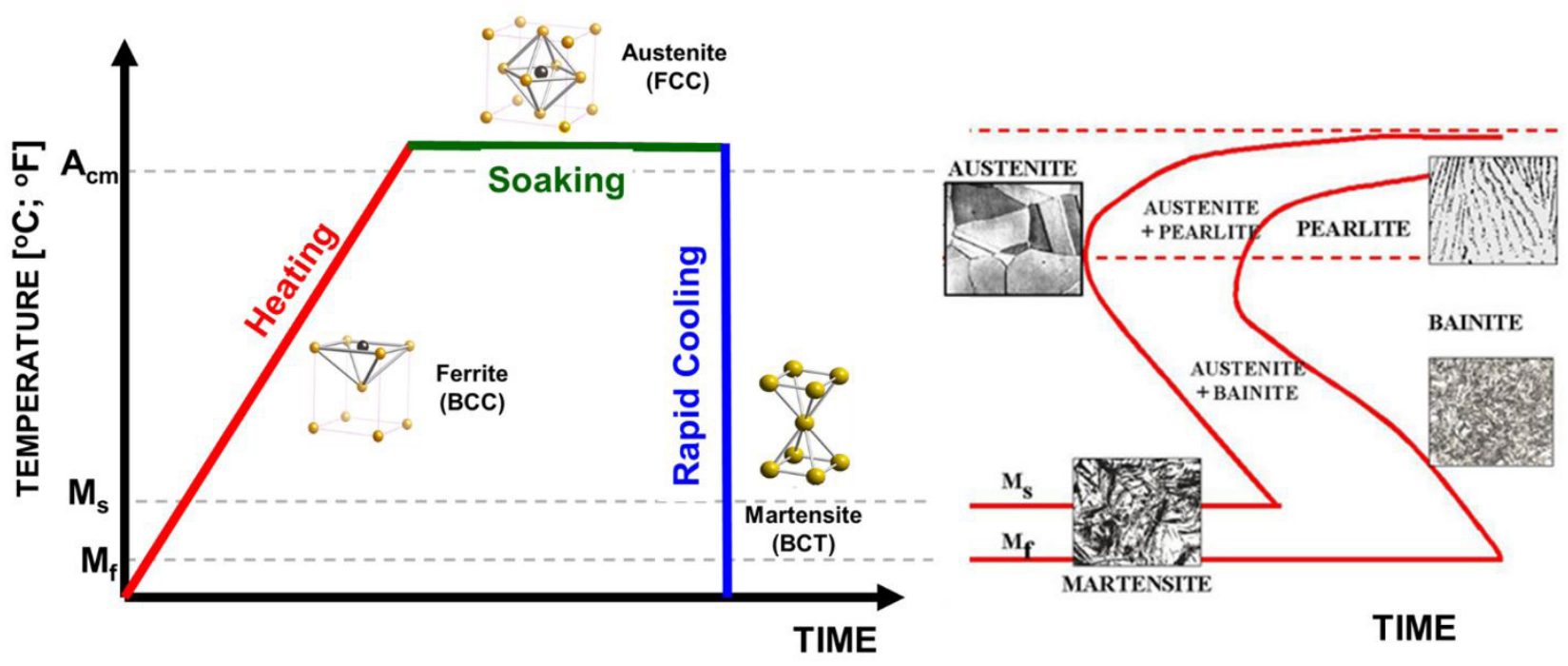

Figure 1. Typical representation of the Quenching cycle and Time - Temperature - Transformation Diagrams. Adapted from [8].
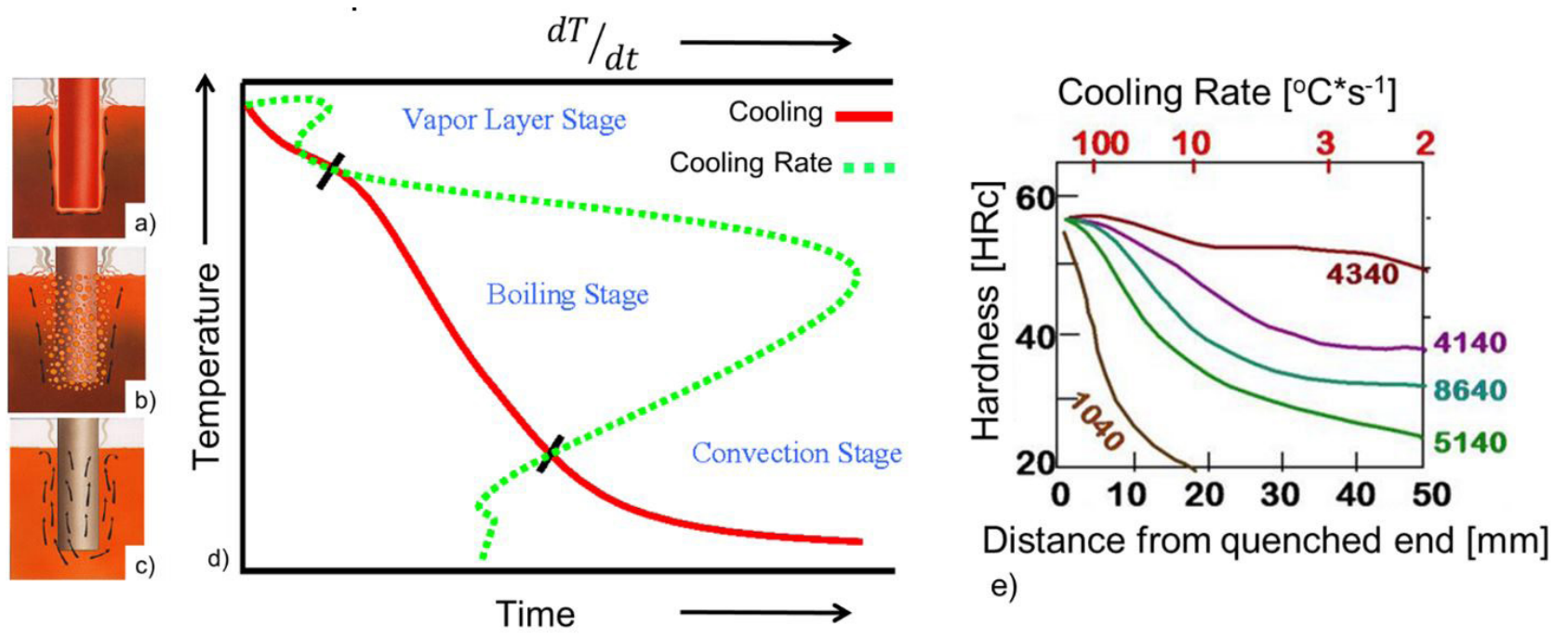

Figure 2. Representation of the Quenching cycle variation and Jominy plot for steel alloys. Adapted from [8,9]. 
the surface expands first, compressing the internal parts. Also, the gradual breakage of the vapor layer promotes even higher stress levels since it intensifies the heat exchange mismatch on different locations of the part [8-15].

One of the possibilities to reduce this effect is the implementation of fluid agitation, which helps in breaking the vapor layer, allowing it to be uniform. Furthermore, the fluidic movement increases the rates of thermal exchange, reducing boiling, and intensifying fluid convection [8-13].

Currently, to increase process control and sustainability, aqueous polymeric solutions (which are a mixture of fluids dissolved in water, forming a homogeneous mixture) can and applied [16-29].

Polymeric cooling media have advantages over traditional fluids since they are biodegradable and have low levels of toxicity, flammability $[18,21,23,29]$. However, one of the most important aspects is the mechanism of breaking the vapor layer, which collapses instantly throughout the body. Thus, the heat exchange is more homogeneous throughout the process, and the residual stresses are considerably reduced $[13,29]$. Moreover, polymers have a high degree of flexibility because they can vary their cooling capacity depending on the concentration at which they are applied. Usually, the greater the amount of polymer in the fluid, the thicker the vapor blanket becomes, making it difficult to break. Therefore, the lower the concentration of the solution, the greater its heat exchange capacity, consequently causing higher levels of hardness and mechanical resistance [16-29].

In this sense, this work evaluated the influence of the cooling medium on the martensite content formation for AISI 4140 steel samples. The materials were quenched in water, mineral oil, and Polyalkylene Glycol solution (PAG). The results showed a significant advance in the PAG application, which guarantees a higher homogenization on martensite distribution at a low decrease in the hardness profile.

Once AISI 4140 grade is a low-alloy steel containing chromium and molybdenum as strengthening agents. Consist of a versatile alloy with good atmospheric corrosion resistance and right overall combinations of strength, toughness, wear-resistance, and fatigue strength. AISI 4140 general engineering applications include components exposed to heavy strain, such as shafts, gear, bolts, chainsaw saber, having a significant impact on Oil \& Gas, Automotive, Civil Construction, Agriculture, and industries $[7,8,30]$.

\section{Materials and methods}

The AISI 4140 steel was subjected to the evaluation of its chemical composition in a Foundry Master Pro spectrometer. The cylindrical $(25.4 \mathrm{~mm}$ in diameter by $10 \mathrm{~mm}$ in length) were quenched in this research.

The quenching procedure started with the heating of the samples to a temperature of $880^{\circ} \mathrm{C}$ (for 1 hour). The heating was carried out in a resistive muffle furnace, brand EDG, model 3000. The samples were cooled in three quenching fluids at room temperature. The fluids were in a $5000 \mathrm{~cm}^{3}$ tank, which was not agitated at all.

Finally, the pieces were tempered at $180^{\circ} \mathrm{C}$ for 1 hour, and the characterization was executed by microstructural, hardness, and X-ray diffraction (XRD) evaluation. The microstructures were captured using a Scanning Electron Microscope Model JSM 6610V, from Jeol. The phase content was made on ImageJ. Microhardness measurements, according to ASTM E384, were made in an HMV 2T equipment, from Shimadzu. We executed eight measurements per sample (at each $1.8 \mathrm{~mm}$ ). The indentation applied a force of 0.3 for 10 seconds [31]. The XRD was performed on a Bruker $\mathrm{X}$-Ray diffractometer, model D8 Advance.

\section{Results and discussion}

Table 1 shows the chemical composition of AISI 4140 steel analyzed in this work.

Figure 3 presented the phases morphologic due to quenching medium variation.

The variation on the heat exchange mechanisms that occur in the internal and external layers results in different cooling rates and phase distribution [31].

All the fluids applied promoted the martensitic transformation. Some of the samples presented a small content of dispersed bainite (due to the presence of $\mathrm{Cr}$, Mo which, increases the austenite field on the TTT curve (Figure 1), promoting the materials homogenization, during the quenching process. Also, no retained austenite was observed in the samples [8-13].

Table 2 shows the percentages of phases depending on the quenching fluid and the location of the observed region obtained by Image $\mathrm{J}$.

The results showed that water promoted greater thermal exchange rate producing more martensite. The PAG medium made the lower martensite content but also the lower variation between samples surface and core. This small variation can contribute to the reduction of residual stress and distortion [18,20,22,24,27].

Ramesh and Prabhu [24] applied a 100\% PAG solution for quenching on AISI 1040 and 1080 carbon steels. The results indicate that AISI 1040 did not form martensite ( $74 \%$

Table 1. Chemical composition of AISI 4140 steel

\begin{tabular}{clllllll}
\hline & \multicolumn{7}{c}{ Chemical Composition of AISI 4140 } \\
\hline \multicolumn{1}{c}{ Element } & \multicolumn{1}{c}{$\mathbf{C}$} & \multicolumn{1}{c}{$\mathbf{C r}$} & \multicolumn{1}{c}{ Mo } & \multicolumn{1}{c}{ Mn } & \multicolumn{1}{c}{ Si } & \multicolumn{1}{c}{ P } & S \\
\hline ASM Limits (\%) & $0.38-0.45$ & $0.80-1.10$ & $0.15-0.25$ & $0.75-1.00$ & $0.20-0.35$ & 0.0035 máx & 0.0040 máx \\
Mesured (\%) & 0.432 & 0.999 & 0.163 & 0.878 & 0.202 & 0.0028 & 0.0033 \\
\hline
\end{tabular}

(weight \%). 


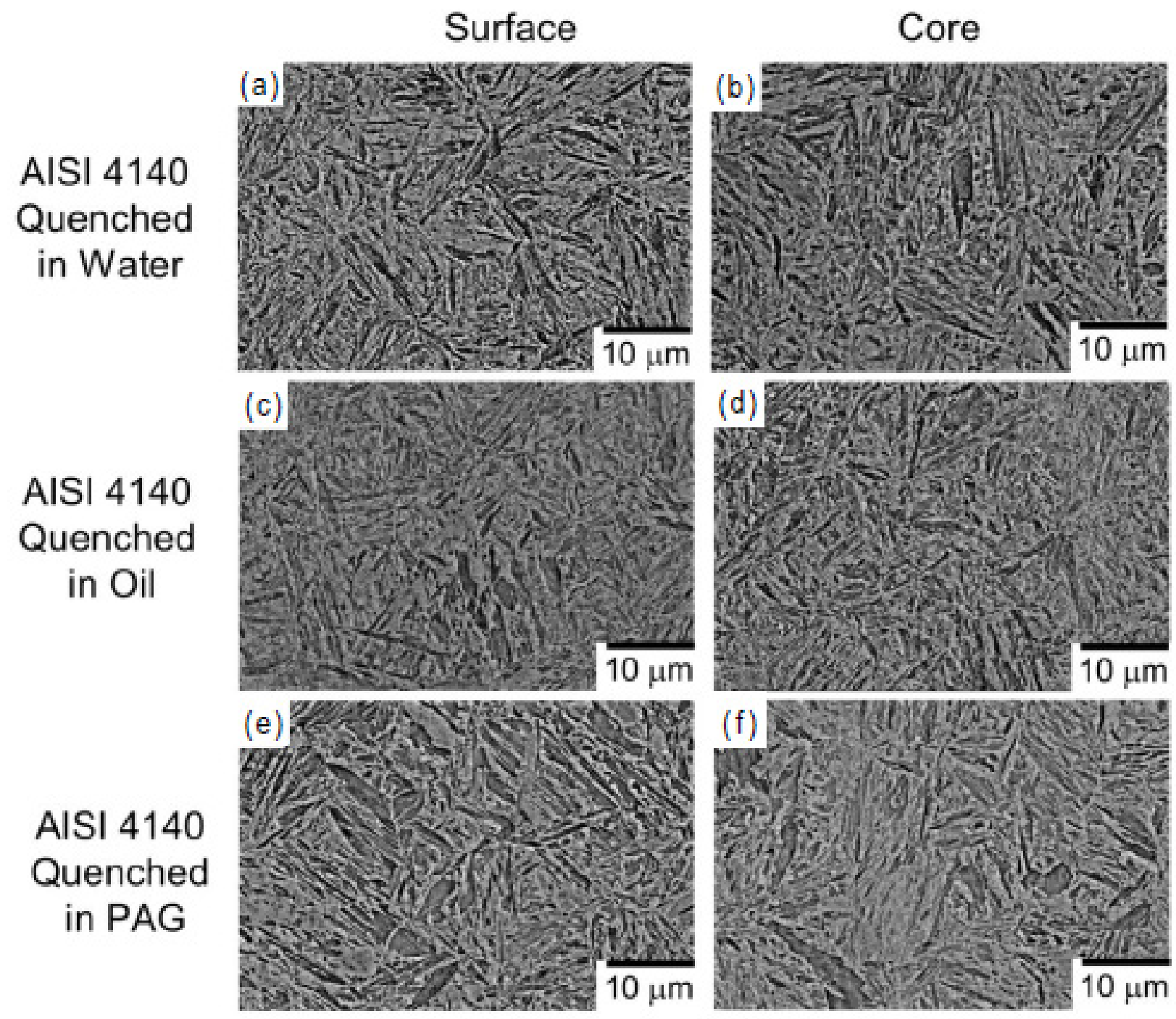

Figure 3. Microstructural representation for: (a) water core, (b) water surface, (c) oil core, (d) oil surface, (e) PAG core, (f) PAG surface.

Table 2. Phase content (\%) due to cooling medium variation on the quenching process of AISI 4140 steels.

\begin{tabular}{|c|c|c|c|c|c|}
\hline \multirow{2}{*}{ Medium } & \multicolumn{2}{|c|}{ Surface } & \multicolumn{2}{|c|}{ Core } & \multirow{2}{*}{$\Delta$} \\
\hline & Martensite & Bainite & Martensite & Bainite & \\
\hline Water & 98.8 & 1.2 & 95.3 & 4.7 & 3.5 \\
\hline Oil & 89.9 & 10.1 & 86.3 & 13.7 & 3.6 \\
\hline PAG & 80.8 & 19.2 & 79.1 & 20.9 & 1.7 \\
\hline
\end{tabular}

bainite, $19 \%$ perlite, and $7 \%$ ferrite), and AISI 1080 form only $6 \%$ of martensite ( $29 \%$ of bainite and $65 \%$ of perlite).

The results demonstrated the PAG applicability for low alloy steels, since AISI 4140 steel achieved at least $79.1 \%$ of martensite content.

Figure 4 shows microhardness variation for the analyzed quenched mediums.

The samples cooled in water showed higher microhardness, followed by oil and, finally, the PAG. For the three situations, there was no sharp drop, and the curves remain practically stable.

Figure 5 shows the results obtained through XRD. The $(1,1,0)$ peaks indicate the martensite phase content.

In general, there is no divergence between the patterns of the spectra presented for the different cooling fluids used in the study. All situations developed three well-defined peaks, at the same diffraction angles, differing only in the intensity of the counts. Two of the Miller indices found to refer to martensite, these indices are $(1,1,0)$ at $2 \theta=44.4^{\circ}$ and 


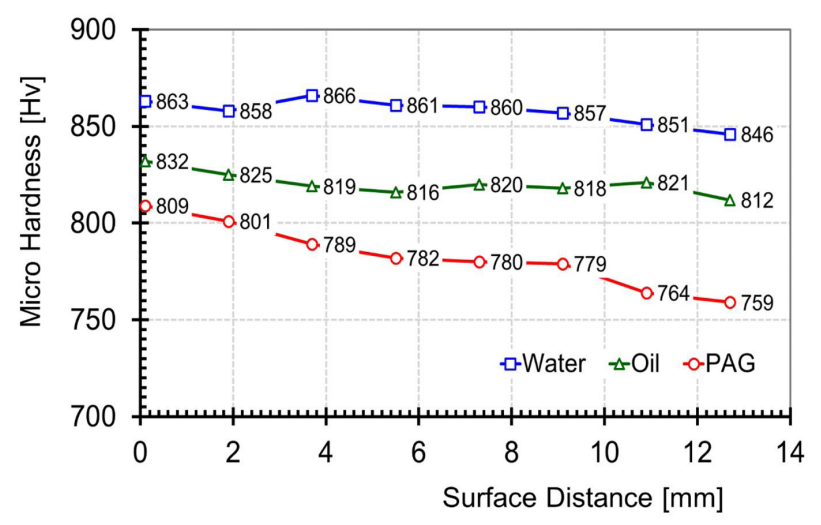

Figure 4. Microhardness curves resulting from each cooling fluid.

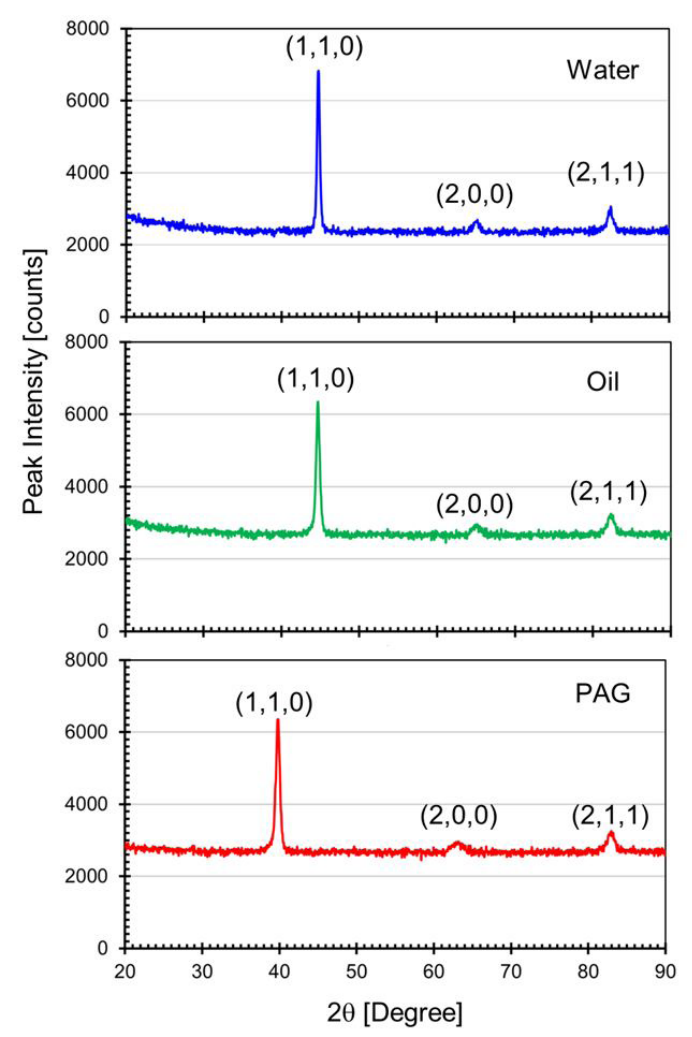

Figure 5. AISI 4140 steels an X-ray diffraction pattern from different cooling mediums.
$(2,1,1)$ at $2 \theta=82^{\circ}$. Consistently with the phase quantifications observed in microscopy, in the materials with the highest amount of martensite, the counts of these peaks were slightly higher. It was found another peak at the angle of $2 \theta=64.7^{\circ}$ $(2,0,0)$. This condition refers to alpha iron, which constitutes bainite. This same index refers to the edge, but in this phase, it constitutes a peak at $2 \theta \approx 51^{\circ}$. The other plans referring to austenite, which are $(1,1,1),(2,0,0),(2,2,0),(3,1,1)$, were not observed. In this way, it is possible to confirm that the results previously observed in microscopy were confirmed by X-ray diffraction, demonstrating a predominance of martensite, with a low presence of bainite and no retained austenite [4,8,13,30,32,33].

Following the modern demands of the combination of performance and sustainability, the results show the applicability of Polymeric solutions as quenched medium for low alloy steels. Besides the decrease in Hardness intensity, the amount of martensite content and variation (between surface and core) indicates the excellent performance of the heat-treated AISI 4140 steels. These materials have applications on Energy, Automotive, Civil Construction, and other special applications $[7,8,25,30]$.

\section{Conclusion}

This work indicates the excellent applicability of $100 \%$ PAG solution as a quenching medium of low alloy steel, such as AISI 4140.

The PAG cooling rate was slower than water and mineral oil, decreasing the martensite content and hardness levels and variation between surface and core measurements (less than $2 \%$ ).

Additionally, no retained austenite was observed in any of the quenching situations. Finally, it is important to remember that the aim of Materials Manufacturing is to guarantee form and performance at low cost and environmental impacts.

\section{Acknowledgements}

This work is dedicated to the memory of Prof. Dr. Telmo R. Strohaecker.

\section{References}

1 Bonamigo AO, Medeiros JLB, Biehl LV, Borges HO, Souza JD. Influência da atmosfera de sinterização na densificação de uma liga Monel 400. Revista Liberato. 2019;20(34):169-176. http://dx.doi.org/10.31514/ rliberato.2019v20n34.p169.

2 Oliveira MU, Medeiros JLB, Biehl LV, Avellaneda CAO, Martins COD, Souza JD, et al. Manufacturing against corrosion: increasing materials performance by the combination of cold work and heat. Materials Science. 2019;26(1):30-33. http://dx.doi.org/10.5755/j01.ms.26.1.17683.

3 Oliveira RCLM, Biehl LV, Medeiros JLB, Ferreira D Fo, Souza J. Análise comparativa entre a têmpera e partição versus a têmpera e revenimento para o aço SAE 4340. Matéria (Rio de Janeiro). 2019;24(3):1-9. http://dx.doi. org/10.1590/s1517-707620190003.0788.

4 Czichos H. Handbook of technical diagnostics. Germany: Springer; 2013. 
5 Souza JD, Motta CAO, Schaeffer L. Utilización de ceniza volante aleada al material compuesto hierro-cobre-grafito mediante un proceso de pulvimetalurgia. Información Tecnológica. 2014;25:21-26. http://dx.doi.org/10.4067/S071807642014000500004.

6 Farag MM. Materials and process selection for engineering design. 3rd ed. USA: Ed. Taylor \& Francis; 2014.

7 Ashby MF. Seleção de materiais no projeto mecânico. 4a ed. Rio de Janeiro: Elsevier; 2012.

8 Totten GE. Steel heat treatment handbook. 2nd ed. NY, USA: CRC Press; 2007.

9 International ASM. ASM handbook: heat treatment. Vol. 4, 10th ed. West Conshohocken: ASM International; 1990.

10 Bicharra EH, Medeiros JLB, Biehl LV, Vieira ER, Silva MD, Souza J, et al. Effect of different cycles of thermal fatigue in steel metallurgical aspects ASTM SA - 516 grade 60. American Journal of Engineering and Applied Sciences. 2020;13(3):436-444. http://dx.doi.org/10.3844/ajeassp.2020.436.444.

11 Krauss G. Martensite in steel: strength and structure. Materials Science and Engineering A. 1999;273-275:40-57.

12 Speich GR, Leslie WC. Tempering of steel. Metallurgical Transactions. 1972;3:1043-1054.

13 Macedo LC, Silva MF Jr, Medeiros JLB, Biehl LV, Martins COD, Souza JD. Efeito do tratamento térmico de alívio de tensões na microestrutura e tamanho de grão de um aço microligado. Revista Liberato. 2018;19:57-65.

14 Martins COD, Strohaecker TR, Rocha AS, Hirsch TK. Application of X-ray diffraction, micromagnetic and hole drilling methods for residual stress determination in a ball bearing steel ring. Experimental Mechanics (Online). Society for Experimental Mechanics. 2005;45(4):344-350.

15 Fernández R, Ferreira S, Ibáñez J, González DG. A multi-scale analysis of the residual stresses developed in a single-phase alloy cylinder after quenching. Materials \& Design. 2017;137:117-127.

16 Buczek A, Telejko T. Investigation of heat transfer coefficient during quenching in various cooling agents. International Journal of Heat and Fluid Flow. 2013;44:358-364.

17 Hernandez HJV, Morales BH. A novel probe design to study wetting front kinematics during forced convective quenching. Experimental Thermal and Fluid Science. 2009;33(5):797-807.

18 Kobasko N, Moskalenko A, Dobryechir V. Research on use of low concentration inverse solubility polymers in water for hardening machine components and tools. EUREKA: Physics and Engineering. 2018;2:63-71.

19 Grum J, Bozic S. Influence of steel masses and quenchants on mechanical properties of steel. International Journal of Materials \& Product Technology. 2005;24(1-4):224-240.

20 Monroe RW, Bates CE. Evaluating quenchants and facilities for hardening steel. Journal of Heat Treating. 1983;3:83-99.

21 Canale LCF, Totten GE. Quenching technology: a selected overview of the current state-of-the-art. Materials Research. 2005;8:461-467.

22 Koudil Z, Ikkene R, Mouzali M. Cooling capacity optimization: calculation of hardening power of aqueous solution based on poly(n-vinyl-2-pyrrolidone). Journal of Materials Engineering and Performance. 2014;23:551-559.

23 Ikkene R, Koudil Z, Mouzali M. Cooling characteristic of polymeric quenchant: calculation of HTC and prediction of microstructure and hardness. Journal of Materials Engineering and Performance. 2014;23:3819-3830.

24 Ramesh G, Ptabhu KN. Effect of polymer concentration on wetting and cooling performance during immersion quenching. Metallurgical and Materials Transactions. B, Process Metallurgy and Materials Processing Science. 2016;47:859-881.

25 Vieira RV, Macedo RJ, Costa VM, Bicharra EH, Piovesan AS, Biehl LV, et al. Evaluation of cooling curves of steel AISI 4140 quenched under different concentrations of polyvinylpyrrolidone. Interciencia Jounal. 2020;45:310-322.

26 Grum J, Bozic S. Influence of steel masses and quenchants on mechanical properties of steel. International Journal of Materials \& Product Technology. 2005;24(1-4):224-240.

27 Vieira RV, Biehl LV, Medeiros JLB, Silva AB, Silva MS. Efeitos da variação da concentração de solução polimérica aquosa a base de PVP na têmpera de aço AISI 4140. Revista Matéria. 2019;24(3):e12425.

28 Totic Y. The corrosion behavior of manganese phosphate coatings applied to AISI 4140 steel subjected to different heat treatments. Surface and Coatings Technology. 2004;200:2711-2717.

29 Hilder NA. Polymer quenchants: a review. Heat Treatments Methods. 1986;13:15-26.

30 Martins COD, Altenhofen A, Clarke TGR, Reguly A. Applying micromagnetic methods for the non-destructive metallurgical characterisation of AISI 4140 steel materials. Insight (Northampton). 2013;55:123-135. 
31 International ASM. ASM Handbook: Metallography and Microstructures. Vol. 1, 10th ed. West Conshohocken: ASM International; 1990.

32 Joseph OO, Joseph OO, Leramo O, Ojudun OS. Effect of heat treatment on microstructure and mechanical properties of SAE 1025 steel. Journal of Materials and Environmental Science 2015;6(1):101-106.

33 Magee CL, Davies RG. On the volume expansion accompanying the f.c.c. to b.c.c. transformation in ferrous alloys. Acta Metallurgica. 1972;20(8):1031-1043.

Received: 18 Aug. 2020

Accepted: 18 Sept. 2020 